\title{
TRPV2 Is Activated by Cannabidiol and Mediates CGRP Release in Cultured Rat Dorsal Root Ganglion Neurons
}

\author{
Ning Qin, Michael P. Neeper, Yi Liu, Tasha L. Hutchinson, Mary Lou Lubin, and Christopher M. Flores \\ Analgesics Team, East Coast Research and Early Development, Johnson \& Johnson Pharmaceutical Research and Development, Spring House, \\ Pennsylvania 19477-0776
}

\begin{abstract}
Transient receptor potential V2 (TRPV2) has been proposed to be a high-threshold thermosensor. However, further elucidation of the channel properties and physiological role of TRPV2 have been hindered by the lack of selective pharmacological tools as well as by the species-dependent differences in the activation of this channel. In the present study, we have used cell-based calcium mobilization and electrophysiological assays to identify and characterize several novel cannabinoid TRPV2 agonists. Among these, cannabidiol was found to be the most robust and potent $\left(\mathrm{EC}_{50}=3.7 \mu \mathrm{M}\right)$, followed by $\Delta^{9}$-tetrahydrocannabinol $\left(\mathrm{EC}_{50}=14 \mu \mathrm{M}\right)$ and cannabinol $\left(\mathrm{EC}_{50}=77.7\right.$ $\mu \mathrm{M})$. We also demonstrated that cannabidiol evoked a concentration-dependent release of calcitonin gene-related peptide (CGRP) from cultured rat dorsal root ganglion neurons in a cannabinoid receptor- and TRPV1-independent manner. Moreover, the cannabidiolevoked CGRP release depended on extracellular calcium and was blocked by the nonselective TRP channel blocker, ruthenium red. We further provide evidence through the use of small interfering RNA knockdown and repetitive stimulation studies, to show that cannabidiol-evoked CGRP release is mediated, at least in part, by TRPV2. Together, these data suggest not only that TRPV2 may comprise a mechanism whereby cannabidiol exerts its clinically beneficial effects in vivo, but also that TRPV2 may constitute a viable, new drug target.
\end{abstract}

Key words: TRPV2; cannabidiol; dorsal root ganglion; pain; agonist; CGRP release

\section{Introduction}

The transient receptor potential V2 (TRPV2) protein, also known as vanilloid receptor-like 1 (VRL-1), is a member of the TRP superfamily of nonselective, ligand-gated cation channels, many of which have been shown to serve as detectors and transducers of thermal sensory stimuli. Functional studies in heterologous expression systems have revealed that TRPV2 responds to noxious heat, with an activation threshold $>52^{\circ} \mathrm{C}$ (Caterina et al., 1999), as well as to changes in osmolarity and to membrane stretch (Muraki et al., 2003). Furthermore, TRPV2 is expressed in medium- to large-diameter $\mathrm{A} \delta$ mechanosensitive and thermosensitive neurons in the rat dorsal root ganglion (DRG) (Caterina et al., 1999), the trigeminal ganglion (Ichikawa and Sugimoto, 2000), and the spinal cord (Lewinter et al., 2004). Moreover, TRPV2 is upregulated in rat DRG after nerve injury (Frederick et al., 2007) and inflammation (Shimosato et al., 2005). Collectively, these data suggest a potential role of TRPV2 in pain sensation. However, compared with TRPV1, TRPV2 has a wider distribution pattern, including brain, skin, spleen, lung, stomach, intestines, bladder, prostate, and peripheral blood (Caterina et al., 1999; Kowase et al., 2002; Kashiba et al., 2004; Saunders et al.,

Received July 9, 2007; revised April 28, 2008; accepted April 30, 2008.

We thank Dr. Michael Finley for helping with data analyses and Yan Wang for providing cell culture expertise.

Correspondence should be addressed to Dr. Ning Qin, Analgesics Team, East Coast Research and Early Development, Johnson \& Johnson Pharmaceutical Research and Development, Welsh and McKean Roads, P.0. Box 776, Spring House, PA 19477-0776. E-mail: nqin@prdus.jnj.com.

DOI:10.1523/JNEUROSCI.0504-08.2008

Copyright $\odot 2008$ Society for Neuroscience $\quad$ 0270-6474/08/286231-08\$15.00/0
2007; Caprodossi et al., 2008), suggesting that TRPV2 may subserve a relatively broad repertoire of physiological functions. In addition, species-dependent activation of TRPV2 in response to noxious heat $\left(\sim 53^{\circ} \mathrm{C}\right)$ and to the nonselective TRP agonist 2 -aminoethoxydiphenyl borate (2-APB) was reported recently (Juvin et al., 2007; Neeper et al., 2007), indicating that the gating mechanisms and the role of this channel in vivo are likely more complicated than were first presumed. Although this complexity has yet to be well elucidated, direct assessment of TRPV2 functions in vivo would be well served by the identification of TRPV2selective agonist/antagonist and the generation of a mouse line lacking expression of TRPV2.

Throughout history, the marijuana plant Cannabis sativa has been reported to be of therapeutic value in the treatment of a variety of ailments, including pain (Di Marzo and De Petrocellis, 2006). $\Delta^{9}$-Tetrahydrocannabinol ( $\Delta^{9}$-THC), the major psychotropic constituent of Cannabis and a moderately potent partial agonist of cannabinoid receptor type $1\left(\mathrm{CB}_{1}\right)$ and type $2\left(\mathrm{CB}_{2}\right)$, has been shown to offer therapeutic benefit but also produces unwanted psychotropic activities that significantly limit its clinical utility (Di Marzo and De Petrocellis, 2006). Cannabidiol (CBD) is a major nonpsychotropic constituent of Cannabis sativa that, unlike $\Delta^{9}$-THC, is virtually inactive at both $\mathrm{CB}_{1}$ and $\mathrm{CB}_{2}$ (Pertwee, 1997). Interestingly, CBD has also been shown to exert both central and peripheral actions with a broad spectrum of therapeutic effects on pain, neuroprotection, anxiety, nausea, cerebral ischemia, type 1 diabetes, rheumatoid arthritis, multiple sclerosis, cancer, and sleep (Mechoulam et al., 2007). The thera- 
peutic efficacy of CBD was further recognized by the recent Canadian approval of Sativex, a 50:50 combination of THC and $\mathrm{CBD}$ in an oral spray, as adjunctive treatment for the relief of neuropathic pain in multiple sclerosis patients and as adjunctive treatment of moderate to severe cancer pain. However, despite CBD's broad therapeutic potential, the mechanism of action and the molecular target of CBD remain a mystery.

In the present study, through the use of calcium imaging and patch-clamp electrophysiological assays, we have discovered and characterized two nonpsychoactive cannabinoids, CBD and cannabinol (CBN), as a novel class of TRPV2 agonists. We further demonstrate that CBD was able to evoke the release of the neurotransmitter CGRP in cultured primary rat DRG neurons and that such release was at least partially mediated by TRPV2.

\section{Materials and Methods}

Reagents. SR141716A and SR144528 were from the National Institute of Mental Health chemical synthesis and drug supply program; cannabidiol, WIN 55,212-2, ( \pm )-11-hydroxy- $\Delta^{9}$-THC, O-1821, O-1918, JWH133, HU-211, HU-308, HU-311, arvanil, and CAY 10429 were purchased from Cayman Chemical, and $\Delta^{9}$-THC, cannabinol, nabilone, CP 55,940, HU-210, WIN 55,212-3, JWH-015, anandamide, palmitic acid, AM404, $2-A G$, and all of the other testing reagents were purchased from Sigma-Aldrich.

Cloning and expression. cDNAs encoding full-length rat TRPV1 and rat TRPA1 were subcloned into the expression vector pCI-neo (Promega). Rat TRPV1 stable cell line was generated by transfecting expression constructs into HEK293 cells and then selecting for G418 resistance (400 $\mu \mathrm{g} / \mathrm{ml})$ at $48 \mathrm{~h}$ after transfection. Clonal lines were then generated by limited dilution of surviving cells at $\sim 5 \mathrm{~d}$ after drug selection. Individual clones were expanded and evaluated by immunoblot and/or calcium mobilization assays to identify clones with the highest TRPV1 expression levels.

Calcium mobilization assays. HEK293 cells stably expressing rat or human TRPV2 (Neeper et al., 2007), rat TRPV1, and HEK293 cells transiently expressing rat TRPA1 were seeded into black-walled, clear-base poly-D-lysine-coated 384-well plates (BD Biosciences) at a density of $8 \times$ $10^{3}$ cells/well in culture media and incubated overnight at $37^{\circ} \mathrm{C}$ and $5 \%$ $\mathrm{CO}_{2}$. The following day, the culture media was replaced with $40 \mu \mathrm{l}$ of Calcium 3 dye (Molecular Devices) dissolved to $0.5 \times$ in complete assay buffer, consisting of $20 \mathrm{~mm}$ HEPES, $137 \mathrm{~mm} \mathrm{NaCl}, 5.4 \mathrm{~mm} \mathrm{KCl}, 0.4 \mathrm{~mm}$ $\mathrm{KH}_{2} \mathrm{PO}_{4}, 0.4 \mathrm{~mm} \mathrm{Na}_{2} \mathrm{HPO}_{4}, 4.2 \mathrm{~mm} \mathrm{NaHCO}, 0.4 \mathrm{~mm} \mathrm{MgSO}_{4}, 1.3 \mathrm{~mm}$ $\mathrm{CaCl}_{2}, 5.6 \mathrm{~mm}$ D-glucose, $2.5 \mathrm{~mm}$ probenecid, and 0.1\% BSA, pH 7.4. Plates were incubated for $35 \mathrm{~min}$ at $37^{\circ} \mathrm{C}$ and $5 \% \mathrm{CO}_{2}$ for dye loading followed by incubation at room temperature for $25 \mathrm{~min}$. Next, $12.5 \mu \mathrm{l}$ of complete assay buffer with or without antagonist was added and incubated for $5 \mathrm{~min}$ at room temperature. Changes in fluorescence at the emission wavelength of $510-570 \mathrm{~nm}$ were measured using a Fluorometric Imaging Plate Reader (FLIPR; Molecular Devices) before and after the addition of $12.5 \mu \mathrm{l}$ of agonist.

Electrophysiology. HEK293 cells stably expressing rat or human TRPV2 were plated on glass coverslips, maintained in $5 \% \mathrm{CO}_{2}$ at $37^{\circ} \mathrm{C}$, and used 1-2 d after plating. Recordings from TRPV2-expressing HEK293 cells were performed using the whole-cell patch-clamp technique. Control and test solutions were applied onto the cell at $0.5 \mathrm{ml} / \mathrm{min}$ via a gravityfed perfusion system. Recordings were performed at $22^{\circ} \mathrm{C}$. Currents were sampled (Digidata 1322A), amplified, and filtered at $2 \mathrm{kHz}$ (Axopatch 200B), then acquired and analyzed using pClamp 9.0 (all instruments/ software from Molecular Devices). CBD-activated currents were elicited with a $600 \mathrm{~ms}$ voltage ramp from $-87 \mathrm{mV}$ to $+23 \mathrm{mV}$ at a sampling rate of $10 \mathrm{kHz}$. The holding potential was $-107 \mathrm{mV}$. The extracellular solution contained the following (in $\mathrm{mm}$ ): $\mathrm{NaCl}$ (132), $\mathrm{KCl}$ (5.4), $\mathrm{CaCl}_{2}$ (1.8), $\mathrm{MgCl}_{2}$ (0.8), HEPES (10), and glucose (10) at $\mathrm{pH}$ 7.4. The pipette solution contained the following (in mM): $\mathrm{CsCl}$ (45), CsF (100), EGTA (5), HEPES (10), and glucose (5) at $\mathrm{pH}$ 7.4. CBD was stored at $-20^{\circ} \mathrm{C}$ as a 100 mM stock solution in $100 \%$ dimethyl sulfoxide, which was diluted into the extracellular solution to a final working concentration on the day of use. Liquid junction potentials were corrected.
Primary culture of rat DRG neurons. Rat DRG neurons were isolated, digested, and plated as previously described for rat trigeminal ganglion isolation (Price et al., 2004). In essence, digested, monodispersed DRG preparations were diluted in DMEM (Mediatech), containing 10\% heatinactivated fetal bovine serum, $1 \times$ penicillin/streptomycin (Invitrogen), $3 \mu \mathrm{g} / \mathrm{ml}$ 5-FDU, $7 \mu \mathrm{g} / \mathrm{ml}$ uridine (Sigma), and freshly added $400 \mathrm{ng} / \mathrm{ml}$ nerve growth factor (Harlan), and distributed into poly-D-lysine-coated 48 -well plates at a density of $\sim 5000$ neurons per well. The media was changed after the first $24 \mathrm{~h}$ and every $48 \mathrm{~h}$ thereafter, each time using media with freshly added NGF.

Neurotransmitter release assay and radioimmunoassay. At 5-8 d after isolation and culture of rat DRG neurons, the media was removed, and the wells were washed three times (200 $\mu$ l volume) in release buffer (HBSS with calcium; Mediatech) supplemented with 4.4 mM HEPES, 4.2 mM sodium bicarbonate, $1 \mathrm{~mm}$ glucose, $0.1 \%$ protease-free BSA, and 20 $\mu \mathrm{M}$ thiorphan immediately before performance of release assays. Washed wells were then incubated with $200 \mu \mathrm{l}$ of buffer in the presence or absence of antagonist for $5 \mathrm{~min}$ at $37^{\circ} \mathrm{C}$. Finally, an equal volume of release buffer containing a $2 \times$ concentration of activator in the presence or absence of antagonist was then added and incubated for $10 \mathrm{~min}$ at $37^{\circ} \mathrm{C}$ before collection and use in the radioimmunoassay (RIA). For repetitive stimulation studies, the first agonist incubation $(400 \mu \mathrm{l})$ was removed after 10 $\min$ at $37^{\circ} \mathrm{C}$, the wells were then washed once, and the second agonist was added (400 $\mu \mathrm{l})$ using the same conditions. CGRP levels in the collections were determined by RIA as described previously (Price et al., 2004). The anti-CGRP antiserum was a kind gift from Dr. Michael Iadarola (National Institutes of Health, Bethesda, MD). Dilutions of known quantities of rat CGRP (Phoenix Pharmaceuticals) were prepared and evaluated along with the sample unknowns to establish a standard curve.

Small interfering RNA knockdown of TRPV2 and TRPA1 expression in primary cultured rat DRG. Rat DRG neurons were harvested and plated as indicated above. At $\sim 48 \mathrm{~h}$ after plating, the media was replaced with media lacking antibiotics, FDU, and uridine, as described above, and containing $300 \mathrm{~nm}$ small interfering RNA (siRNA) transfection mix prepared using Dharmafect 3 , as recommended by the manufacturer (Dharmacon). Each well of a 48-well plate received a pool of four siRNA oligomers targeting either rat TRPV2 or TRPA1 or a nontargeting siRNA control mRNA sequence (SMARTpools catalog \#L-091197-00, L-100647-00, or D-001205-13, respectively; Dharmacon). After $\sim 96 \mathrm{~h}$ after transfection, CGRP release was performed and measured using a rat CGRP ELISA kit available from Cayman Chemical using the methods recommended by the vendor. RNA was isolated from the cells of the transfected wells using an RNAqueous-micro RNA kit (Ambion), converted to cDNA and amplified using TaqMan reagent kits available from Applied Biosystems, as recommended by the manufacturer, and assayed on an Applied Biosystems 7900HT real-time PCR instrument. To standardize the amount of total RNA added to each reaction, the glyceraldehyde-3-phosphate dehydrogenase (GAPDH) mRNA levels were measured as an endogenous control.

Data analysis. For calcium mobilization assay, peak intracellular calcium responses were measured as the difference between the peak fluorescence intensities in the presence and absence of agonist. These values were normalized to the maximum response to a saturating concentration of the agonist tested. In the case of antagonist testing, responses were normalized to the difference between the peak fluorescence intensity in the presence of agonist alone and that in the presence of agonist and the highest, saturating concentration of the antagonist. All concentrationresponse data were fitted to a logistic function as follows: $Y=$ Bottom + $($ Top - Bottom $) /\left(1+10^{\left(\log \mathrm{C}_{50}-X\right) \times \text { Hillslope }}\right) ; X$ is the logarithm of concentration. $Y$ is the response; $Y$ starts at Bottom and goes to Top with a sigmoid shape. $\mathrm{C}_{50}$ is the $\mathrm{EC}_{50}$ (agonist) or $\mathrm{IC}_{50}$ (antagonist) value. Data fitting was performed using GraphPad Prism 4.02. To quantitate the relative amount of specific mRNA in the samples, a comparative $\mathrm{C}_{\mathrm{T}}$ method was used, with the arithmetic formula of $2^{-\Delta \Delta C T}$, after normalizing the amount of specific mRNA against the endogenous control GAPDH mRNA level $\left(\Delta \mathrm{C}_{\mathrm{T}}\right)$, followed by normalizing against the corresponding mRNA levels in the nontarget siRNA treatment samples $\left(\Delta \Delta \mathrm{C}_{\mathrm{T}}\right)$. Where appropriate, a $t$ test was performed to determine the statistical significance. Data are expressed as mean \pm SEM. 
Table 1. Activation of TRPV2, TRPA1, and TRPV1

\begin{tabular}{|c|c|c|c|c|c|c|}
\hline \multirow[b]{2}{*}{ Compound } & \multicolumn{2}{|l|}{ Rat TRPV2 } & \multicolumn{2}{|l|}{ Rat TRPA1 } & \multicolumn{2}{|l|}{ Rat TRPV1 } \\
\hline & $\%$ Response at $100 \mu \mathrm{m}$ & $\mathrm{EC}_{50}(\mu \mathrm{M})$ & $\%$ Response at $100 \mu \mathrm{m}$ & $\mathrm{EC}_{50}(\mu \mathrm{M})$ & $\%$ Response at $100 \mu \mathrm{m}$ & $\mathrm{EC}_{50}(\mu \mathrm{M})$ \\
\hline $2-\mathrm{APB}(15 \mu \mathrm{M})^{a}$ & 100 & $10.0 \pm 2.8$ & & & 64 & 33.6 \\
\hline Mustard oil (50 $\mu \mathrm{m})$ & 8 & & 100 & 7.1 & 22 & \\
\hline Capsaicin (500 nм) & & & & & 100 & 0.02 \\
\hline$\Delta^{9}-\mathrm{THC}$ & 98 & 15.5 & 62 & 32.3 & 0 & \\
\hline Cannabidiol & 160 & 3.7 & 100 & 81.4 & 21 & \\
\hline Cannabinol & 67 & 77.7 & 22 & & 0 & \\
\hline 11-hydroxy- $\Delta^{9}$-THC & 57 & & 2 & & 24 & \\
\hline $0-1821^{a}$ & 93 & & 7 & & 15 & \\
\hline 0-1918 & 6 & & 0 & & 14 & \\
\hline CAY 10429 & 0 & & 86 & 9.0 & 1 & \\
\hline Nabilone & 58 & & 4 & & 26 & \\
\hline CP55940 & 42 & & 48 & & 0 & \\
\hline HU-210 & 38 & & 1 & & & \\
\hline HU-211 & 30 & & 0 & & 1 & \\
\hline HU-308 & 10 & & 12 & & 23 & \\
\hline $\mathrm{HU}-331(50 \mu \mathrm{M})^{a}$ & 46 & & 95 & 3.2 & 37 & \\
\hline WIN 55212-2 $2^{a}$ & 0 & & 82 & 9.8 & 40 & \\
\hline WIN $55212-3^{a}$ & 7 & & 95 & 21.7 & 43 & \\
\hline JWH-015 & 14 & & 22 & & 58 & 41.2 \\
\hline JWH-133 & 4 & & & & 0 & \\
\hline Anandamide & 0 & & 0 & & 92 & 6.9 \\
\hline $2-A G$ & 29 & & 0 & & 61 & 8.4 \\
\hline Arvanil & 11 & & & & 113 & 0.02 \\
\hline AM404 & 6 & & 0 & & 104 & 0.47 \\
\hline
\end{tabular}

The percentage responses were normalized to $15 \mu \mathrm{m}$ 2-APB (for TRPV2), $50 \mu \mathrm{m}$ mustard oil (for TRPA1), and $0.5 \mu \mathrm{m}$ capsaicin (for TRPV1).

${ }^{a}$ A response was observed in HEK293 parental cells, which was subtracted.

\section{Results}

\section{Activation of rat TRPV2 by CBD and other cannabinoids}

Previously, we identified $\Delta^{9}$-THC as a novel TRPV2 agonist, using a cell-based calcium mobilization assay (Neeper et al., 2007). However, $\Delta^{9}$-THC shows poor selectivity, because it was also able to activate TRPA1 (Jordt et al., 2004). To identify a more selective TRPV2 agonist, we selected 20 additional cannabinoids and cannabinoid analogs and determined their agonistic activity at rat TRPV2 at doses ranging from 0.01 to $100 \mu \mathrm{M}$. As shown in Table 1, CBD and CBN, each reportedly nonpsychoactive components of Cannabis, were demonstrated to activate TRPV2. CBD was found to be the most potent and efficacious agonist, inducing a higher calcium influx than that induced by the same concentration $(100 \mu \mathrm{M})$ of control agonist 2-APB, followed by $\Delta^{9}$-THC and CBN.

The agonistic properties of these compounds were then further characterized. As shown in Figure 1, B and $E$, respectively, CBD $(10 \mu \mathrm{M})$ and CBN $(100 \mu \mathrm{M})$ induced significant calcium influx in rat TRPV2-expressing HEK293 cells, whereas virtually no changes in calcium influx were observed in the parental HEK293 cells under the same conditions. Furthermore, the calcium influx induced by CBD and CBN was concentration dependent, with $\mathrm{EC}_{50}$ values of 3.7 and $77.7 \mu \mathrm{M}$, respectively (Fig. $1 C, F)$, and was inhibited by preincubation with ruthenium red (RR) (Fig. 1D, G). Importantly, these responses were not sensitive to the TRPV1 antagonist capsazepine (CPZ) (data not shown).

$\Delta^{9}$-THC and CBN were previously reported to be activators of TRPA1 (Jordt et al., 2004), and CBD was previously shown to activate human TRPV1 (Bisogno et al., 2001). We therefore tested our panel of cannabinoid compounds against both TRPV1 and TRPA1. As shown in Table 1 , in addition to $\Delta^{9}$-THC, several other cannabinoids were shown to act as TRPA1 agonists, including CBD, WIN 55,212-2, WIN 55,212-3, CAY 10429, and HU331. However, under the same conditions, $100 \mu \mathrm{M}$ CBN only slightly increased calcium influx in TRPA1-expressing cells (Table 1). Among these TRPA1 agonists, HU-331 was the most potent activator of TRPA1 $\left(\mathrm{EC}_{50}=3.2 \mu \mathrm{M}\right)$, followed by CAY 10429 $\left(\mathrm{EC}_{50}=9.0 \mu \mathrm{M}\right)$, WIN 55,212-2 $\left(\mathrm{EC}_{50}=9.8 \mu \mathrm{M}\right)$, WIN 55,212-3 $\left(\mathrm{EC}_{50}=21.7 \mu \mathrm{M}\right), \Delta^{9}-\mathrm{THC}\left(\mathrm{EC}_{50}=32.3 \mu \mathrm{M}\right)$, and $\mathrm{CBD}\left(\mathrm{EC}_{50}=\right.$ $81.4 \mu \mathrm{M})$. One cannabinoid, JWH-015, was identified to be a TRPV1 agonist. Interestingly, CBD $(100 \mu \mathrm{M})$ did not significantly increase calcium influx in rat TRPV1-expressing cells, although the cells were activated by the prototypical TRPV1 agonist capsaicin (CAP) as well as by several other agonists, such as anandamide, arvanil, and AM404 (Table 1), confirming the other expected activities of our cell lines. In summary, we have identified several cannabinoids and synthetic cannabinoid analogs capable of selectively activating TRPV2 (although CBD activates both TRPV2 and TRPA1, it is $>21$-fold more potent at TRPV2 than at TRPA1), TRPA1 (HU-331, WIN 55,212-2, WIN 55,212-3, and CAY 10429), or both TRPV2 and TRPA1 ( $\Delta^{9}$-THC and CBN).

\section{Activation of human TRPV2 by CBD and other cannabinoids} Previously, we reported on the species-dependent activation properties of TRPV2, whereby rodent TRPV2 could be activated by the nonselective agonist 2 -APB,$\Delta^{9}$-THC, or noxious heat $\left(\sim 53^{\circ} \mathrm{C}\right)$, whereas human TRPV2 was insensitive to $2-\mathrm{APB}$ and noxious heat, but could be activated by $\Delta^{9}$-THC. Here, we tested the ability of CBD to induce calcium influx in human TRPV2expressing cells, using a cell-based calcium mobilization assay. As shown in Figure 2, after addition of CBD, the calcium influx was markedly increased. As with the activation of rat TRPV2, the effect was concentration dependent, with an $\mathrm{EC}_{50}$ value of 31.7 $\mu \mathrm{M}$, and was inhibited by preincubation with RR, which exhibited an $\mathrm{IC}_{50}$ value of $17 \mu \mathrm{M}$ when tested in the presence of $10 \mu \mathrm{M}$ CBD. In addition, CBN was also able to activate human TRPV2 but with lower potency compared with rat TRPV2 (data not shown). 
A<smiles>C=C(C)C1(C)CCC(C)=C[C@H]1c1c(O)cc(CCCCC)cc1O</smiles>

cannabidiol (CBD)

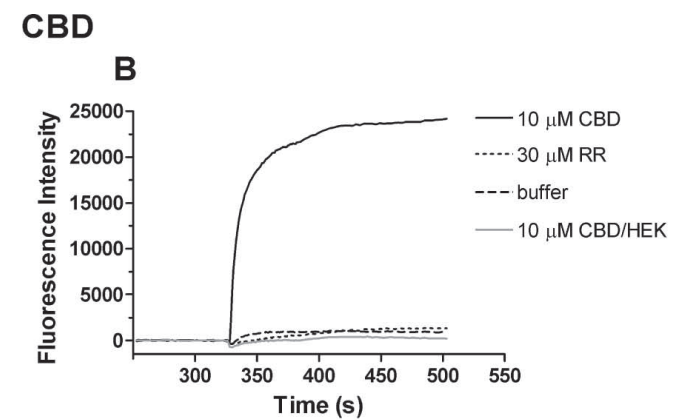

CBN

E

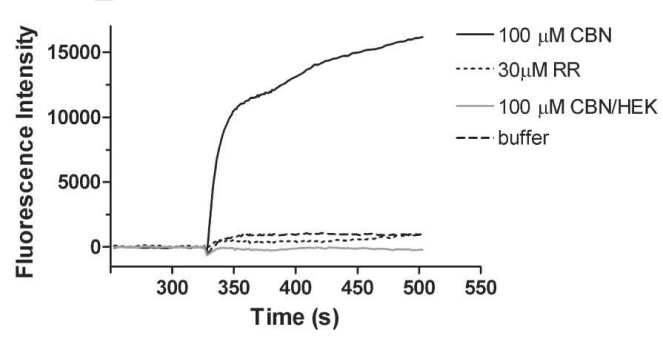<smiles>CCCCCc1cc(O)c2c(c1)OC(C)(C)c1ccc(C)cc1-2</smiles>

cannabinol (CBN)
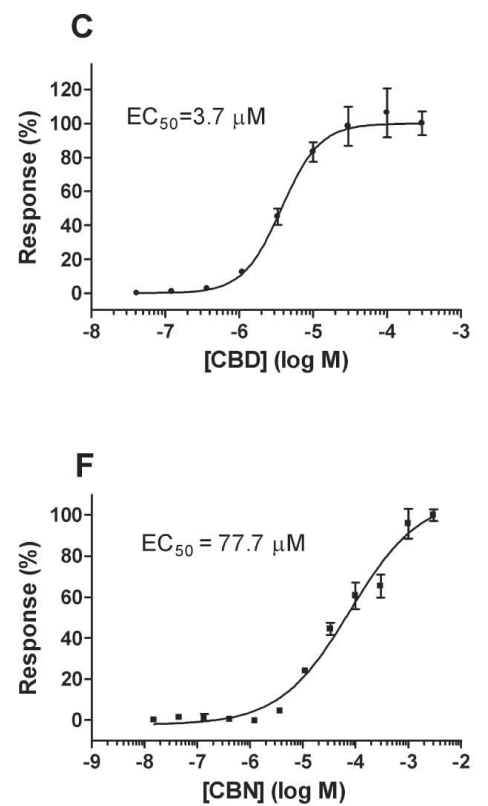

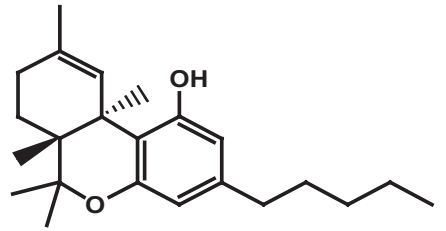

$\Delta^{9}$-tetrahydroocannabinol $\left(\Delta^{9}-\mathrm{THC}\right)$

Figure 1. Activation of rat TRPV2 (rTRPV2) by cannabinoids in calcium mobilization assay. $\boldsymbol{A}$, Structures of selected cannabinoids. $\boldsymbol{B}-\boldsymbol{G}$, Representative fluorescence traces of the time course ( $\boldsymbol{B}$, $\boldsymbol{E}$ ), concentration-response relationship $(\boldsymbol{C}, \boldsymbol{F})$, and RR antagonism $(\boldsymbol{D}, \boldsymbol{G})$ of rTRPV2 activation by $30 \mu \mathrm{m}(B D(\boldsymbol{B}-\boldsymbol{D})$ and $100 \mu \mathrm{m}(B N(\boldsymbol{E}-\boldsymbol{G})$. In $\boldsymbol{B}$ and $\boldsymbol{E}$, a robust calcium influx was evoked after addition of CBD or CBN (solid black line); the responses can be completely blocked by $30 \mu \mathrm{MR}$ (dotted black line); little fluorescence intensity change was observed in the absence of cannabinoids (dashed black line) or in HEK293 parental cells in the presence of the same concentration of cannabinoids (solid gray line).

A

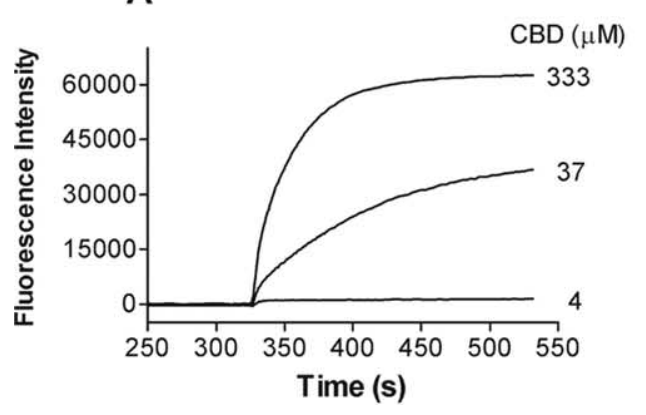

B

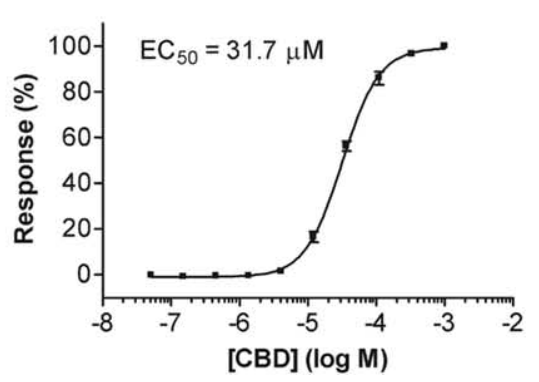

C

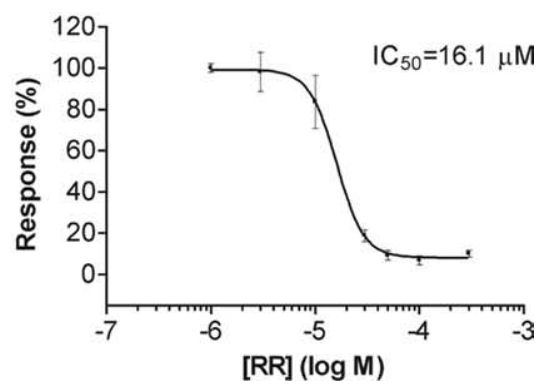

Figure 2. Activation of human TRPV2 (hTRPV2) by CBD in calcium mobilization assay. $\boldsymbol{A}-\boldsymbol{C}$, Representative fluorescence traces of the time course $(\boldsymbol{A})$, concentration-response relationship $(\boldsymbol{B})$, and RR antagonism $(C)$ of $h$ TRPV2 activation by CBD.

Electrophysiological characterization of CBD-evoked currents in human and rat TRPV2-expressing HEK293 cells In patch-clamp studies, CBD elicited RR (10 $\mu \mathrm{M})$-sensitive currents in HEK293 cells stably expressing either rat (Fig. 3A) or human (Fig. 3B) TRPV2, but had no effect on the current amplitude in untransfected cells (data not shown). The current-voltage relationship in the presence of $\mathrm{CBD}$ showed outward rectification for both rat (Fig. 3C) and human (Fig. 3D) TRPV2, with a reversal potential near $0 \mathrm{mV}(-1.4 \pm 3.5 \mathrm{mV}$ for rat TRPV2, $n=6$;
$2.6 \pm 0.9 \mathrm{mV}$ for human TRPV2, $n=5$ ), similar to what has been reported for rat TRPV2 activation by 2-APB (Caterina et al., 1999; Hu et al., 2004; Neeper et al., 2007).

Pharmacological characterization of CBD- and CBN-evoked CGRP release from rat DRG neurons

Some cannabinoids, such as $\Delta^{9}$-THC and WIN 55,212-2, have been shown to evoke CGRP release from perivascular sensory nerve endings innervating rat mesenteric arteries and from rat 
A

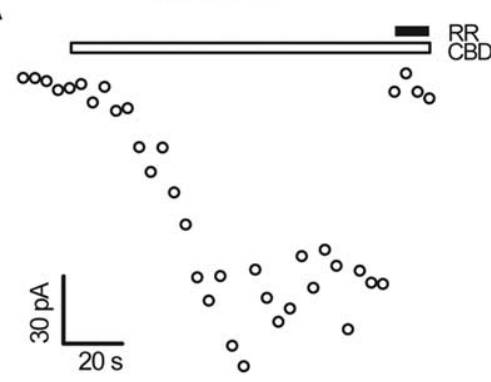

C

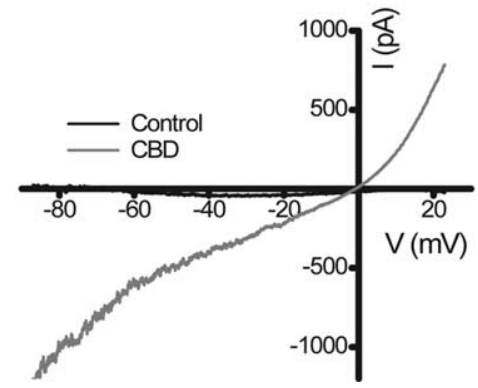

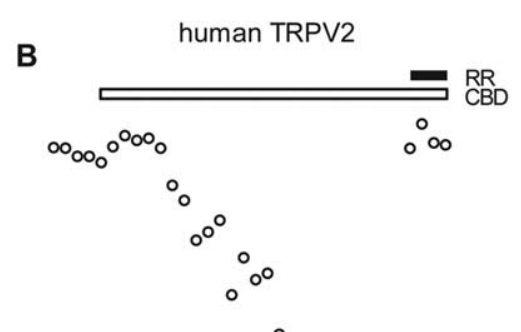

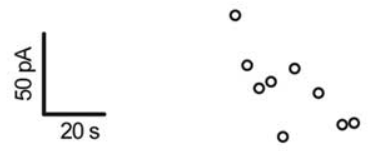

D

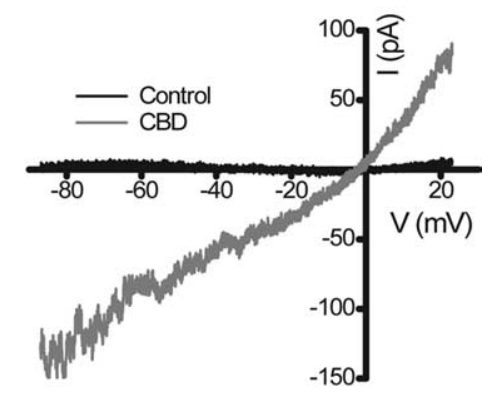

Figure 3. Activation of TRPV2 by CBD in whole-cell patch clamp. $A, B$, Time course of activation by $30 \mu \mathrm{m} C B D$ at $-87 \mathrm{mV}$ for $\operatorname{rat}(\boldsymbol{A})$ and human $(\boldsymbol{B})$ TRPV2. $\boldsymbol{C}, \boldsymbol{D}$, Current-voltage $(I-V)$ relationships of rat $(\boldsymbol{C})$ and human $(\boldsymbol{D})$ TRPV2 in response to $30 \mu \mathrm{m}$ CBD. The currents were elicited with a continuous voltage ramp from $-87 \mathrm{mV}$ to $+23 \mathrm{mV}$ once every $4 \mathrm{~s}$. The $I-V$ plots are averages of five current traces and are subtracted from responses in the concurrent presence of CBD $(30 \mu \mathrm{M})$ and $\mathrm{RR}(10 \mu \mathrm{M})$.
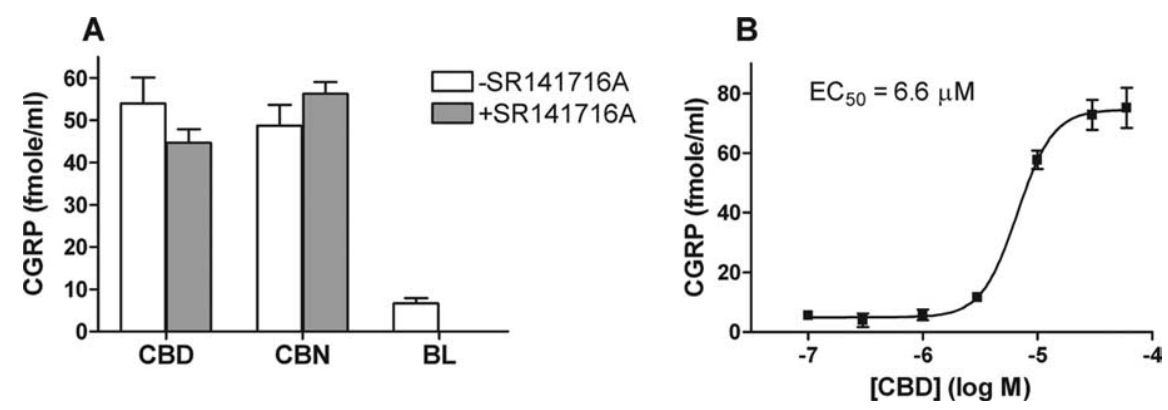

Figure 4. $\quad \mathrm{CB}_{1}$-independent $\mathrm{CBD}$ - and $\mathrm{CBN}$-evoked CGRP release. $A$, Effect of selected cannabinoids on CGRP release from cultured rat DRG neurons. Shown is (GRP release from neuronal cultures preincubated with buffer (open bar) or $10 \mu \mathrm{m}$ SR141716A (gray bars) and then challenged with $20 \mu \mathrm{M} C B D, 20 \mu \mathrm{M} C B N$, or buffer (BL) as indicated in Materials and Methods. $B, C G R P$ release from rat DRG neurons as a function of CBD concentration.

trigeminal ganglion neurons in culture (Zygmunt et al., 2002; Price et al., 2004). Here, we explored the ability of CBD and CBN to evoke CGRP release from cultured rat DRG neurons in the presence and absence of the $\mathrm{CB}_{1}$ antagonist SR141716A. As shown in Figure $4 A$, both cannabinoids were able to evoke CGRP release from rat DRG neurons. Interestingly, the CGRP release evoked by these cannabinoids appeared to be independent of $\mathrm{CB}_{1}$, because the release evoked by $\mathrm{CBN}$ or $\mathrm{CBD}$ was insensitive to the presence of $10 \mu \mathrm{M}$ SR141716A, a $\mathrm{CB}_{1}$-specific antagonist. Furthermore, CBD-evoked CGRP release appeared to be concentration dependent, with an $\mathrm{EC}_{50}$ value of $6.6 \mu \mathrm{M}$ (Fig. $4 \mathrm{~B}$ ).

\section{TRPV2 mediation of CBD-evoked CGRP release from}

\section{DRG neurons}

We further examined the mechanism of CBD-evoked CGRP release in rat cultured DRG neurons. As expected, $100 \mathrm{~nm}$ CAP evoked a substantial $(\sim 10$-fold) increase in CGRP release from rat DRG neurons. This release appeared to be mediated by

TRPV1, because it was dependent on the presence of extracellular calcium and could be fully blocked by either $10 \mu \mathrm{M}$ RR or the TRPV1-selective antagonist CPZ but not by $10 \mu \mathrm{M}$ of the $\mathrm{CB}_{1}$ antagonist SR141716A or the $\mathrm{CB}_{2}$ antagonist SR144528 (Fig. 5A). We next tested CGRP release evoked by 30 $\mu \mathrm{M}$ CBD under the same conditions (Fig. $5 B)$. As with CAP-evoked CGRP release, CBD-evoked CGRP release was insensitive to either SR141716A or SR144528, suggesting that the release was independent of $\mathrm{CB}_{1}$ and $\mathrm{CB}_{2}$. However, in contrast to CAPevoked release, $\mathrm{CBD}$-evoked CGRP release was insensitive to $10 \mu \mathrm{M} \mathrm{CPZ}$, but could be completely blocked by RR, suggesting the potential involvement of a TRP channel other than TRPV1. The effect of extracellular calcium on the CBD-evoked CGRP release was also examined. In the absence of extracellular calcium, CGRP release evoked by $30 \mu \mathrm{M}$ CBD was reduced to near basal levels, clearly indicating the dependence of extracellular calcium on neurotransmitter release. Furthermore, the CBD-evoked CGRP release appeared to be independent of voltage-gated calcium channels, ionotropic glutamate receptors, or $\mathrm{G}_{\mathrm{i}} / \mathrm{G}_{\mathrm{o}}$-coupled receptors, because its release was not blocked by calcicludine $(0.08$ $\mu \mathrm{M})$, nimodipine $(0.1 \mu \mathrm{M}), \omega$-conotoxin GVIA $(0.1 \mu \mathrm{M})$, MVIIC $(0.1 \mu \mathrm{M}), \mathrm{MK}-801$ $(3 \mu \mathrm{M}), \mathrm{CNQX}(300 \mu \mathrm{M})$, or pertussis toxin (150 ng/ml) (data not shown).

Calcium mobilization studies (Table 1) demonstrated that CBD activates not only TRPV2 but also, to a lesser extent, TRPA1. To determine whether TRPA1 contributed to CBD-evoked CGRP release, we tested the effect of mustard oil (MO), a selective agonist of TRPA1 but not TRPV2 (Table $1)$, on cultured rat DRG neurons. Like $\mathrm{CBD}, 30 \mu \mathrm{M} \mathrm{MO}$ also evoked a significant CGRP release from rat DRG neurons, which was independent of $\mathrm{CB}_{1} / \mathrm{CB}_{2}$ as well as TRPV1, but could be blocked by $10 \mu \mathrm{M} R \mathrm{R}$ and was significantly reduced in the absence of extracellular calcium (Fig. 5C). These common responses complicated our efforts to distinguish between TRPV2 and TRPA1 as potential mediators of CBDevoked CGRP release. To further dissect the excitatory effects of $\mathrm{CBD}$ on DRG neurons, we designed a repetitive stimulation experiment in which an agonist (designated the first addition) was added to cultured neurons for $10 \mathrm{~min}$ at $37^{\circ} \mathrm{C}$ to evoke CGRP release, followed by agonist removal before the addition of a second agonist (designated the second addition) under the same conditions. The agonist used for the second addition was either the same agonist or a different agonist from that used in the first addition. Thus, as shown in Figure 5D, when DRG neurons were first treated with CAP, MO, or CBD, CGRP release was dramatically reduced by a second addition of the same agonist. However, when the DRG neurons were first treated with CBD, MO was still able to evoke $>80 \%$ CGRP release compared with the release by the first addition of MO. Similar results were also obtained in a 
reciprocal experiment, in which the cultured DRG neurons were first treated with $\mathrm{MO}$ and then followed by CBD. In this case, the second addition of CBD still evoked $>60 \%$ CGRP release when compared with that stimulated by a first addition of CBD, suggesting that CGRP release evoked by CBD and MO was largely mediated by different channels. To better understand the involvement of TRPV2 in CBD-evoked CGRP release, two sets of SMARTpool oligos (Dharmacon) derived from either the rat TRPV2 sequence or the rat TRPA1 sequence were used to specifically knock down TRPV2 or TRPA1 channel expression, respectively, in cultured primary DRG neurons. At $96 \mathrm{~h}$ after transfection with 300 nM rat TRPV2 siRNAs, the mRNA level of TRPV2 in DRG neurons was reduced by $58 \%$ (Fig. 6A), without significantly affecting the levels of TRPV1 or TRPA1 mRNA. Similar results were also obtained when 300 nM rat TRPA1 siRNA was used, in which the TRPA1 mRNA levels were reduced by $70 \%$, without affecting the mRNA levels of TRPV1 or TRPV2. Furthermore, the mRNA levels of TRPV1, TRPV2, or TRPA1 were not affected when DRG neurons were transfected with a comparable pool of nontarget siRNA, as a negative control. As shown in Figure $6 B$, in TRPV2 siRNA-transfected DRG neurons, CBD-evoked CGRP release was reduced by $54 \%$ compared with nontarget siRNAtransfected DRG neurons (from $39.4 \pm 2.3 \mathrm{fmole} / \mathrm{ml}$ to $19 \pm 4.3$ fmole $/ \mathrm{ml}$ ). Under the same conditions, the MO- or CAP-evoked CGRP release was unaffected by either TRPV2 siRNA-transfected or nontarget siRNA-transfected DRG neurons. Similarly, in TRPA1 siRNA-transfected DRG neurons, the MO-evoked CGRP release was reduced by $88 \%$ compared with nontarget siRNAtransfected DRG neurons (from $23.0 \pm 1.3 \mathrm{fmole} / \mathrm{ml}$ to $7.0 \pm 0.7$ fmole/ml), whereas CBD- or CAP-evoked CGRP was unchanged. In all cases, the total amount of CGRP released represented $30-$ $45 \%$ of total content, as measured by permeabilizing the neurons at the conclusion of the assay. We conclude that TRPV2 appears to mediate CBD-evoked CGRP release in cultured rat DRG neurons to a much greater extent than TRPA1.

\section{Discussion}

Since the end of the last decade, when TRPV2 was first reported to be a potential thermal sensor, relatively few advances have been made in the understanding of the biophysical properties and physiological roles of this channel. This gap in knowledge is at least partly attributable to the previous lack of selective pharmacological tools available to study TRPV2 and the species-specific differences in its activation properties. Toward filling this gap, we report here the identification and characterization of a novel cannabinoid class of TRPV2 activators, including CBD, CBN, and $\Delta^{9}$-THC. Several lines of evidence indicate that some thermosensitive TRP channels can serve as so-called ionotropic cannabinoid receptors. For example, TRPA1 can be activated by $\Delta^{9}$ THC, CBN, or WIN 55,212-2 (Jordt et al., 2004; Akopian et al., 2008), whereas TRPV1 is reported to be responsive to the endocannabinoids anandamide, AM404, and olvanil (Zygmunt et al., 1999; Ralevic et al., 2001) as well as to CBD (Bisogno et al., 2001).

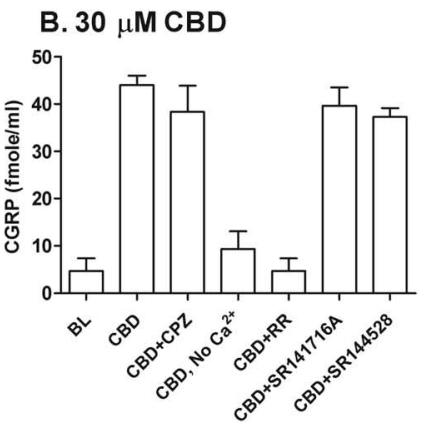

D. Repeated stimulation

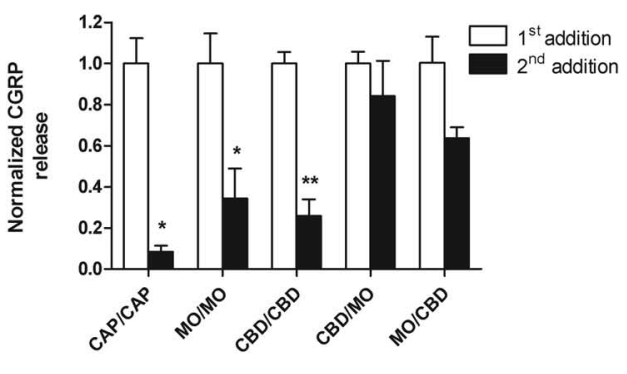

Figure 5. TRP channel-mediated CBD-evoked GRP release. $A-C$, CGRP release in response to $100 \mathrm{~nm} C A P(A), 30 \mu \mathrm{m} C B D(B)$, CGRP release in response to a second exposure of the same or a different agonist (e.g., $\mathrm{MO} / \mathrm{CBD}$ indicates first treatment with $\mathrm{MO}$ followed by (BD). ${ }^{*} p<0.05 ;{ }^{* *} p<0.01$.

However, to our knowledge, no selective TRPV2 agonist has been previously identified, nor has any extensive study been described about TRPV2 serving as an ionotropic cannabinoid receptor. Our counterscreening of selected cannabinoid compounds against TRPA1- and TRPV1-expressing cell lines further confirmed most of the above referenced findings from other laboratories. However, we found no significant agonistic activity of CBD on rat TRPV1. Instead, we found CBD to exhibit agonistic activity at TRPA1, with at least 20 -fold lower potency than at TRPV2, thus suggesting that CBD is a relatively selective TRPV2 agonist. Possible explanations for this discrepancy of the CBD action at TRPV1 include species-specific activity differences, because human TRPV1 was used in the previous study, and/or differences in assay conditions (Bisogno et al., 2001).

The peripheral and central termini of sensory neurons are important sites of release of various neuropeptides, including CGRP, that mediate the process of neurogenic inflammation. Considerable evidence has also implicated the involvement of CGRP in neuronal excitation (Olesen et al., 2004; Ambalavanar et al., 2006). THC and CBN were previously shown to evoke a calcium-dependent, $\mathrm{CB}_{1}$ - and $\mathrm{CB}_{2}$-independent release of CGRP from capsaicin-sensitive perivascular sensory nerves (Zygmunt et al., 2002) and primary sensory neurons in culture (Price et al., 2004). Interestingly, this cannabinoid-evoked release was abolished in the presence of RR but remained intact in cultured neurons from TRPV1 knock-out mice, suggesting that CGRP release in response to THC and CBN was mediated by a TRP channel other than TRPV1. A recent study also demonstrated that both THC and CBN are agonists of the TRPA1 channel (Jordt et al., 2004). In the present study, we demonstrated that CBD and CBN both activated TRPV2 and evoked CGRP release from cultured rat DRG neurons. Furthermore, the effects of CBD and CBN appeared to be $\mathrm{CB}_{1}$ independent. We also tested the synthetic cannabinoids WIN 55,212-2 and WIN 55,212-3, neither of which 
A
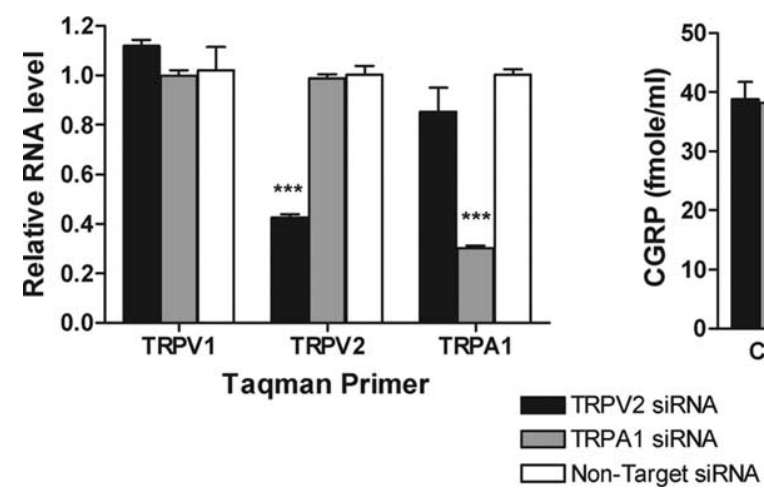

Figure 6. The effects of TRPV2 or TRPA1 siRNA knockdown on CBD- and MO-evoked CGRP release from rat DRG neurons. $A$, Relative mRNA levels of TRPV1, TRPV2, and TRPA1 in TRPV2, TRPA1, or nontarget siRNA-transfected DRG neurons. $B$, CBD (30 $\mu \mathrm{M})$-, M0 (30 $\mu \mathrm{M})$-, or CAP (100 nM)-evoked CGRP release in TRPV2, TRPA1, or nontarget siRNA-transfected DRG neurons. ${ }^{* *} p<$ $0.01 ;{ }^{* * *} p<0.001$.

appeared to activate rat TRPV2. Interestingly, both were able to activate TRPA1 (Table 1), suggesting that TRPA1 may be involved in WIN-evoked CGRP release from trigeminal neurons, consistent with a previous report (Jeske et al., 2006).

CBD is widely reported to have broad therapeutic applications and yet appears to lack the unwanted psychotropic liability of THC (Mechoulam et al., 2007). CBD is also an active component of the marketed analgesic Sativex. Among the newly identified TRPV2 agonists described here, CBD is particularly interesting, because it was the most potent and selective and its in vivo mechanism of action and molecular target are heretofore unknown. Several hypotheses have been proposed previously to explain the mechanism of action of CBD: (1) CBD is a noncompetitive binder to and allosteric modulator of $\mu$ - and $\delta$-opioid receptors (Kathmann et al., 2006); (2) CBD acts as an antagonist of $\mathrm{CB}_{1}$ and $\mathrm{CB}_{2}$ (Thomas et al., 2007); (3) CBD activates TRPV1 channels (Bisogno et al., 2001); (4) CBD indirectly increases levels of anandamide by inhibiting its uptake and hydrolysis (Watanabe et al., 1998); (5) CBD inhibits the adenosine transporter (Carrier et al., 2006); and (6) CBD activates a novel, as yet unidentified cannabinoid receptor that is structurally distinct from $\mathrm{CB}_{1}$ and $\mathrm{CB}_{2}$ (Grotenhermen, 2005). The pharmacological profile of $\mathrm{CBD}$ evoked CGRP release presented here suggests that it is unlikely to be mediated by opioid receptors, $\mathrm{CB}_{1} / \mathrm{CB}_{2}$, or TRPV1, because it was insensitive to pertussis toxin, $\mathrm{CB}_{1}$ - and $\mathrm{CB}_{2}$-selective antagonists, or a TRPV1-selective antagonist. The endocannabinoid anandamide was previously demonstrated to evoke CGRP release via activation of TRPV1 (Zygmunt et al., 1999). However, the lack of involvement of TRPV1 in CBD-evoked CGRP release in our studies also rules out any mechanism whereby the putative inhibition of anandamide uptake and hydrolysis by CBD would subsequently increase CGRP release via TRPV1. In this study, we further found that CBD evoked a concentration-dependent release of CGRP from cultured rat DRG neurons, which depended on extracellular calcium, and was insensitive to various blockers of either voltage-gated calcium channels or ionotropic glutamate receptors (data not shown), or to the TRPA1 agonist/desensitizer MO; however, it was blocked by RR. From these results together with the study of selective knockdown of TRPV2 or TRPA1 mRNA levels, we conclude that at least a significant component of the CBD-evoked CGRP release shown here was mediated by TRPV2.

Although the in vivo functions of TRPV2 still remain to be elucidated, limited evidence suggests that it may act as a noxious heat sensor and, therefore, play a role in thermal nociception. Independently, CBD has demonstrated a broad therapeutic value without clearly defined mechanisms of action. Our findings that CBD activates TRPV2 in a heterologous expression system and, further, that CBD evokes CGRP release via TRPV2 in cultured rat DRG neurons provide evidence of a potential molecular mechanism whereby $\mathrm{CBD}$ exerts its effects in vivo. However, the results of this seminal study cannot account for all of the mechanisms underlying the therapeutic actions of CBD and, in fact, may appear to some extent paradoxical. For example, CBD has demonstrated the ability to reverse both thermal and mechanical hyperalgesia in models of either inflammatory pain (complete Freund's adjuvant) or neuropathic pain (chronic constriction injury) (Costa et al., 2007), and these antihyperalgesic effects were shown to be independent of $\mathrm{CB}_{1}$ and $\mathrm{CB}_{2}$. To the extent that such antihyperalgesic effects were shown to be sensitive to capsazepine (Costa et al., 2007), which does not block TRPV2 in our hands, it stands to reason that the molecular target through which these effects are produced may not be TRPV2. Moreover, if these antinociceptive properties of CBD were mediated by TRPV2, then one might expect that CBD should inhibit CGRP release, because CGRP has been widely used as a marker of nociceptor activation. This apparent paradox, however, may have an explanation similar to that provided for anandamide, which also activates a noxious heat sensor (i.e., TRPV1) and evokes the release of CGRP in cultured neurons, yet is nonpungent and is antinociceptive in animal models of pain. Toward reconciling these observations, it has been proposed that anandamide stimulation causes a change in channel properties, such that TRPV1 becomes desensitized to further stimulation, essentially reducing further nociceptive channel responses (Zygmunt et al., 1999). In support of this hypothesis, repetitive application of CBD significantly reduced CGRP release from cultured DRG neurons in this study, although we did not observe obvious desensitization of TRPV2 channel in our patch-clamp study (data not shown). To refute the possibility that decreased CGRP release to repeated CBD treatment was a result of peptide depletion rather than desensitization, we showed that the majority of CGRP content still remained after repeated stimulation. On the other hand, interpretations involving the differential distribution of the TRP channels under study on distinct subpopulations of CGRP-containing DRG neurons cannot be ruled out. Finally, it has been postulated that cannabidiol may interact with a heretofore orphan G-proteincoupled receptor called GPR55; however, although some studies have shown activation of GPR55 by cannabidiol (Ryberg et al., 2007), others have not (Lauckner et al., 2008). Clearly, further studies need to be conducted to fully elucidate the mechanism of $\mathrm{CBD}$ antinociceptive effect, and to this end, mice lacking expression of functional TRPV2 could prove particularly useful.

In conclusion, we have identified and characterized a novel class of cannabinoid TRPV2 agonists, including CBD, a therapeutically active constituent of Cannabis sativa. Moreover, we have demonstrated that CBD is able to evoke CGRP release from cultured DRG neurons in a manner that is at least partially dependent on TRPV2. Together, these data suggest not only that 
TRPV2 may comprise a mechanism whereby CBD exerts its clinically beneficial effects in vivo, but also that TRPV2 may constitute a viable, new therapeutic target for directed drug discovery efforts.

During the revision process, a study was published describing activation of rat TRPA1 (with a potency higher than that found in this study) and inhibition of rat TRPM8 by CBD and other phytocannabinoids (De Petrocellis et al., 2008).

\section{References}

Akopian AN, Ruparel NB, Patwardhan A, Hargreaves KM (2008) Cannabinoids desensitize capsaicin and mustard oil responses in sensory neurons via TRPA1 activation. J Neurosci 28:1064-1075.

Ambalavanar R, Moritani M, Moutanni A, Gangula P, Yallampalli C, Dessem D (2006) Deep tissue inflammation upregulates neuropeptides and evokes nociceptive behaviors which are modulated by a neuropeptide antagonist. Pain 120:53-68.

Bisogno T, Hanus L, De Petrocellis L, Tchilibon S, Ponde DE, Brandi I, Moriello AS, Davis JB, Mechoulam R, Di Marzo V (2001) Molecular targets for cannabidiol and its synthetic analogues: effect on vanilloid VR1 receptors and on the cellular uptake and enzymatic hydrolysis of anandamide. Br J Pharmacol 134:845-852.

Caprodossi S, Lucciarini R, Amantini C, Nabissi M, Canesin G, Ballarini P, Di Spilimbergo A, Cardarelli MA, Servi L, Mammana G, Santoni G (2008) Transient receptor potential vanilloid type 2 (TRPV2) expression in normal urothelium and in urothelial carcinoma of human bladder: correlation with the pathologic stage. Eur Urol, in press.

Carrier EJ, Auchampach JA, Hillard CJ (2006) Inhibition of an equilibrative nucleoside transporter by cannabidiol: a mechanism of cannabinoid immunosuppression. Proc Natl Acad Sci USA 103:7895-7900.

Caterina MJ, Rosen TA, Tominaga M, Brake AJ, Julius D (1999) A capsaicin-receptor homologue with a high threshold for noxious heat. Nature 398:436-441.

Costa B, Trovato AE, Comelli F, Giagnoni G, Colleoni M (2007) The nonpsychoactive cannabis constituent cannabidiol is an orally effective therapeutic agent in rat chronic inflammatory and neuropathic pain. Eur J Pharmacol 556:75-83.

De Petrocellis L, Vellani V, Schiano-Moriello A, Marini P, Magherini PC, Orlando P, Di Marzo V (2008) Plant-derived cannabinoids modulate the activity of transient receptor potential channels of ankyrin type-1 (TRPA1) and melastatin type-8 (TRPM-8). J Pharmacol Exp Ther 325:1007-1015.

Di Marzo V, De Petrocellis L (2006) Plant, synthetic, and endogenous cannabinoids in medicine. Annu Rev Med 57:553-574.

Frederick J, Buck ME, Matson DJ, Cortright DN (2007) Increased TRPA1, TRPM8, and TRPV2 expression in dorsal root ganglia by nerve injury. Biochem Biophys Res Commun 358:1058-1064.

Grotenhermen F (2005) Cannabinoids. Curr Drug Targets CNS Neurol Disord 4:507-530.

Hu H-Z, Gu Q, Wang C, Colton CK, Tang J, Kinoshita-Kawada M, Lee L-Y, Wood JD, Zhu MX (2004) 2-Aminoethoxydiphenyl borate is a common activator of TRPV1, TRPV2, and TRPV3. J Biol Chem 279:35741-35748.

Ichikawa H, Sugimoto T (2000) Vanilloid receptor 1-like receptorimmunoreactive primary sensory neurons in the rat trigeminal nervous system. Neuroscience 101:719-725.

Jeske NA, Patwardhan AM, Gamper N, Price TJ, Akopian AN, Hargreaves KM (2006) Cannabinoid WIN 55,212-2 regulates TRPV1 phosphorylation in sensory neurons. J Biol Chem 281:32879-32890.

Jordt S-E, Bautista DM, Chuang H-h, McKemy DD, Zygmunt PM, Hogestatt ED, Meng ID, Julius D (2004) Mustard oils and cannabinoids excite sensory nerve fibres through the TRP channel ANKTM1. Nature 427:260-265.

Juvin V, Penna A, Chemin J, Lin Y-L, Rassendren F-A (2007) Pharmacological characterization and molecular determinants of the activation of transient receptor potential V2 channel orthologs by 2-aminoethoxydiphenyl borate. Mol Pharmacol 72:1258-1268.

Kashiba H, Uchida Y, Takeda D, Nishigori A, Ueda Y, Kuribayashi K, Ohshima M (2004) TRPV2-immunoreactive intrinsic neurons in the rat intestine. Neurosci Lett 366:193-196.

Kathmann M, Flau K, Redmer A, Trankle C, Schlicker E (2006) Cannabidiol is an allosteric modulator at mu- and delta-opioid receptors. Naunyn Schmiedebergs Arch Pharmacol 372:354-361.

Kowase T, Nakazato Y, Yoko OH, Morikawa A, Kojima I (2002) Immunohistochemical localization of growth factor-regulated channel (GRC) in human tissues. Endocr J 49:349-355.

Lauckner JE, Jensen JB, Chen H-Y, Lu H-C, Hille B, Mackie K (2008) GPR55 is a cannabinoid receptor that increases intracellular calcium and inhibits M current. Proc Natl Acad Sci USA 105:2699-2704.

Lewinter RD, Skinner K, Julius D, Basbaum AI (2004) Immunoreactive TRPV-2 (VRL-1), a capsaicin receptor homolog, in the spinal cord of the rat. J Comp Neurol 470:400-408.

Mechoulam R, Peters M, Murillo-Rodriguez E, Hanus LO (2007) Cannabidiol—recent advances. Chem Biodivers 4:1678-1692.

Muraki K, Iwata Y, Katanosaka Y, Ito T, Ohya S, Shigekawa M, Imaizumi Y (2003) TRPV2 is a component of osmotically sensitive cation channels in murine aortic myocytes. Circ Res 93:829-838.

Neeper MP, Liu Y, Hutchinson TL, Wang Y, Flores CM, Qin N (2007) Activation properties of heterologously expressed mammalian TRPV2: evidence for species dependence. J Biol Chem 282:15894-15902.

Olesen J, Diener HC, Husstedt IW, Goadsby PJ, Hall D, Meier U, Pollentier S, Lesko LM (2004) Calcitonin gene-related peptide receptor antagonist BIBN 4096 BS for the acute treatment of migraine. N Engl J Med 350:1104-1110.

Pertwee RG (1997) Pharmacology of cannabinoid CB1 and CB2 receptors. Pharmacol Ther 74:129-180.

Price TJ, Patwardhan A, Akopian AN, Hargreaves KM, Flores CM (2004) Cannabinoid receptor-independent actions of the aminoalkylindole WIN 55,212-2 on trigeminal sensory neurons. Br J Pharmacol 142:257-266.

Ralevic V, Kendall DA, Jerman JC, Middlemiss DN, Smart D (2001) Cannabinoid activation of recombinant and endogenous vanilloid receptors. Eur J Pharmacol 424:211-219.

Ryberg E, Larsson N, Sjogren S, Hjorth S, Hermansson NO, Leonova J, Elebring T, Nilsson K, Drmota T, Greasley PJ (2007) The orphan receptor GPR55 is a novel cannabinoid receptor. Br J Pharmacol 152:1092-1101.

Saunders CIM, Kunde DA, Crawford A, Geraghty DP (2007) Expression of transient receptor potential vanilloid 1 (TRPV1) and 2 (TRPV2) in human peripheral blood. Mol Immunol 44:1429-1435.

Shimosato G, Amaya F, Ueda M, Tanaka Y, Decosterd I, Tanaka M (2005) Peripheral inflammation induces up-regulation of TRPV2 expression in rat DRG. Pain 119:225-232.

Thomas A, Baillie GL, Phillips AM, Razdan RK, Ross RA, Pertwee RG (2007) Cannabidiol displays unexpectedly high potency as an antagonist of CB1 and CB2 receptor agonists in vitro. Br J Pharmacol 150:613-623.

Watanabe K, Ogi H, Nakamura S, Kayano Y, Matsunaga T, Yoshimura H, Yamamoto I (1998) Distribution and characterization of anandamide amidohydrolase in mouse brain and liver. Life Sci 62:1223-1229.

Zygmunt PM, Petersson J, Andersson DA, Chuang H, Sorgard M, Di Marzo V, Julius D, Hogestatt ED (1999) Vanilloid receptors on sensory nerves mediate the vasodilator action of anandamide. Nature 400:452-457.

Zygmunt PM, Andersson DA, Hogestatt ED (2002) Delta 9-tetrahydrocannabinol and cannabinol activate capsaicin-sensitive sensory nerves via a $\mathrm{CB} 1$ and $\mathrm{CB} 2$ cannabinoid receptor-independent mechanism. J Neurosci 22:4720-4727. 